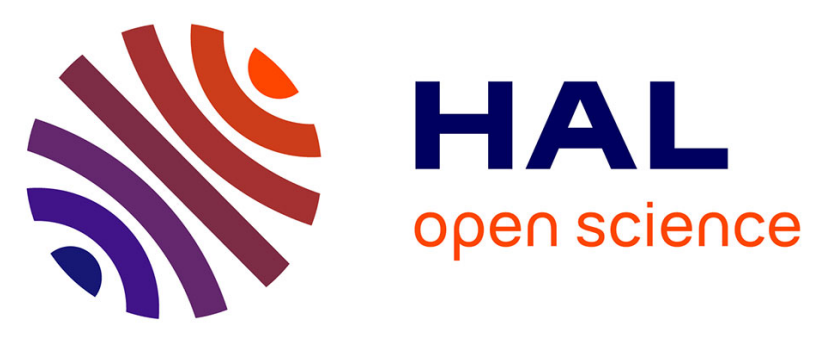

\title{
Cross coupling of alkylsilicates with acyl chlorides via photoredox/nickel dual catalysis: a new synthesis method for ketones
}

Etienne Levernier, Vincent Corcé, Louise-Marie Rakotoarison, Adrien Smith, Mengxue Zhang, Stephanie Ognier, Michael Tatoulian, Cyril Ollivier, Louis Fensterbank

\section{To cite this version:}

Etienne Levernier, Vincent Corcé, Louise-Marie Rakotoarison, Adrien Smith, Mengxue Zhang, et al.. Cross coupling of alkylsilicates with acyl chlorides via photoredox/nickel dual catalysis: a new synthesis method for ketones. Organic Chemistry Frontiers, 2019, 6 (9), pp.1378-1382. 10.1039/C9QO00092E . hal-02189397

\section{HAL Id: hal-02189397 https://hal.sorbonne-universite.fr/hal-02189397}

Submitted on 19 Jul 2019

HAL is a multi-disciplinary open access archive for the deposit and dissemination of scientific research documents, whether they are published or not. The documents may come from teaching and research institutions in France or abroad, or from public or private research centers.
L'archive ouverte pluridisciplinaire HAL, est destinée au dépôt et à la diffusion de documents scientifiques de niveau recherche, publiés ou non, émanant des établissements d'enseignement et de recherche français ou étrangers, des laboratoires publics ou privés. 


\title{
Cross Coupling of Alkylsilicates with Acylchlorides via Photoredox/Nickel Dual Catalysis. A New Synthesis of Ketones
}

\author{
Etienne Levernier ${ }^{\mathrm{a}}$, Vincent Corcéa ${ }^{\mathrm{a}}$, Louise-Marie Rakotoarison ${ }^{\mathrm{a}}$, Adrien Smith $^{\mathrm{a}}$, Mengxue Zhang $^{\mathrm{b}}$, \\ Stephanie Ognier ${ }^{\mathrm{b}}$, Michael Tatoulian ${ }^{\mathrm{b}}$, Cyril Ollivier ${ }^{\mathrm{a} *}$, Louis Fensterbank ${ }^{\mathrm{a} *}$

\begin{abstract}
Photoredox/Nickel dual catalysis using easy oxydized bis-catecholato hypercoordinated silicon derivatives as radical sources and acylchlorides as electrophile allows a new method of formation of dialkyl and alkyl-aryl ketones as well as
\end{abstract} \\ dibenzyl ketones which are less easily accessed. Flow chemistry can be used
}

\section{Introduction}

Ketones are ubiquitous molecules in our daily life. They are also pivotal substrates in organic chemistry. ${ }^{1}$ While a myriad of synthetic methods have been developed to reach them, a recurrent pitfall lies in the fact that the keto group is a highly reactive function which can overreact in a lot of experimental conditions. Recently, the emergence of dual photoredox/nickel catalysis ${ }^{2}$ resulting from the pioneer works of the groups of MacMillan and Doyle $^{3}$ and of Molander ${ }^{4}$ has profoundly changed the way of envisaging C-C bond formation by involving radical precursors such as carboxylates, ${ }^{5}$ methylanilines or cyclic amines, ${ }^{3,6}$ trifluoroborates and related derivatives, ${ }^{7}$ silicates, ${ }^{8}$ dihydropyridines ${ }^{9}$ as well as sulfinate ${ }^{10}$ and electrophiles such as aryl and vinyl halides and also $\mathrm{Csp}^{2}-O$ electrophiles. ${ }^{6,11}$

In addition of being environmentally friendly and very mild, the photoredox conditions used in these reactions are usually compatible with many functionalities. ${ }^{12}$ They have also been found to be compatible for the delivery of ketones. ${ }^{8 i, 13}$ For instance, Doyle and co-workers showed that it is possible to obtain $\alpha$-amino ketones by using $\mathrm{N}$-aryl amines and electrophiles such as anhydrides or activated esters. ${ }^{14}$ In the same vein, Molander et al. used this approach to achieve the coupling reaction between acyl chlorides and trifluoroborates as radical precursors to obtain

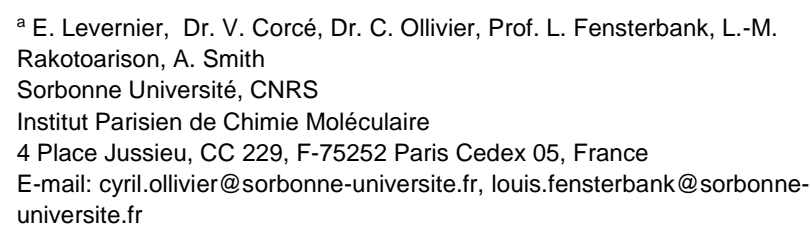

functionalized ketones. ${ }^{15}$ Nevertheless, this transformation relies on conditions involving the use of additives such as 2,6-lutidine or fluoride salts and does not provide highly enolizable benzylic ketones which are difficult to access. For these reasons, we turned our attention to the reactivity of the highly soluble and easily oxidized silicates toward carboxylic acid derivatives and particularly acyl chlorides in order to obtain benzylic and alkyl ketones.

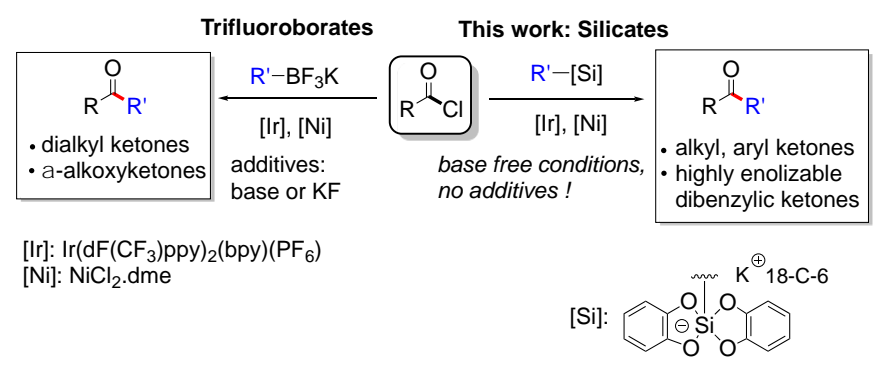

Scheme 1 Formation of ketones via dual photoredox/Ni catalysis using acid chloride as electrophiles

\section{Results and discussion}

We first tried this reaction with 1.5 equiv of cyclohexyl silicate $\mathbf{2 a}$ $\left(E_{o x}=0.69 \mathrm{~V}\right.$ vs SCE) as the radical source and 1 equiv of the benzoyl chloride as the electrophile in the presence of $\mathrm{Ru}(\mathrm{bpy})_{3}\left(\mathrm{PF}_{6}\right)$ as photocatalyst, $\mathrm{NiCl}_{2}$.dme and dtbbpy (4,4'-di-tert-butyl-2,2'dipyridyl) as ligand in THF under blue LED irradiation at room temperature. Gratifyingly, the expected ketone 3a was obtained in $64 \%$ yield. Following this encouraging result, we searched for the best conditions to achieve this reaction (Table 1 ). The organic photocatalyst 4CzIPN, known to have a long lived excited state and a high oxidative potential $\left(\tau=5100 \mathrm{~ns}, \mathrm{E}_{1 / 2}\left(\operatorname{Ir}\left(\mathrm{PC}^{*}\right) / \operatorname{Ir}\left(\mathrm{PC}^{-}\right)=+1.59 \mathrm{~V}\right.\right.$ vs $\mathrm{SCE})^{16,17}$ and previously used to oxidize silicates, ${ }^{18}$ gave ketone $\mathbf{3 a}$ in $52 \%$ yield (entry 2). To our delight, iridium photocatalyst $\operatorname{Ir}\left(\mathrm{dF}\left(\mathrm{CF}_{3}\right) \mathrm{ppy}\right)_{2}(\mathrm{bpy})\left(\mathrm{PF}_{6}\right)$ provided the best yield of coupling product 3a (72\%). Other solvents (dichloromethane, acetonitrile) 
and nickel catalysts, for instance $\mathrm{Ni}(\mathrm{COD})_{2}$ ) as nickel (0) source were screened but did not result in any improvement. So the $\operatorname{Ir}\left(\mathrm{dF}\left(\mathrm{CF}_{3}\right) \mathrm{ppy}\right)_{2}(\mathrm{bpy})\left(\mathrm{PF}_{6}\right) / \mathrm{NiCl}_{2}$.dme dual catalytic system was selected and gave the best results.

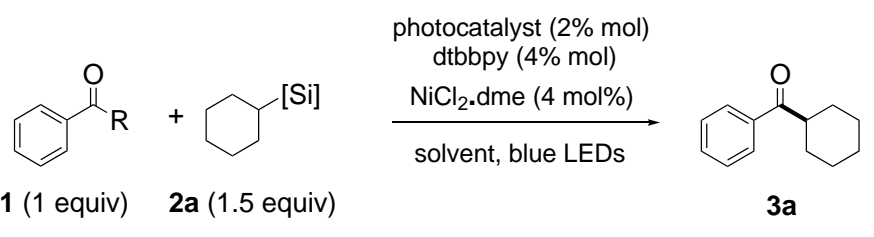

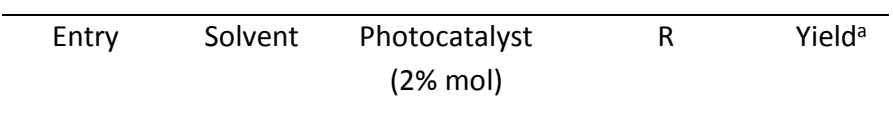

\begin{tabular}{|c|c|c|c|c|}
\hline 1 & THF & {$[\mathrm{Ru}]^{\mathrm{b}}$} & $\mathrm{Cl}$ & $64 \%$ \\
\hline 2 & THF & 4CZIPN & $\mathrm{Cl}$ & $52 \%$ \\
\hline 3 & THF & {$[\mathrm{Ir}]^{\mathrm{c}}$} & $\mathrm{Cl}$ & $54 \%$ \\
\hline 4 & DMF & {$[\mathrm{Ir}]^{\mathrm{c}}$} & $\mathrm{Cl}$ & $6 \%$ \\
\hline 5 & THF & {$[\mathrm{Ir}]^{\mathrm{c}}$} & $\mathrm{Cl}$ & $72 \%$ \\
\hline $6^{d}$ & THF & {$[\mathrm{Ir}]^{\mathrm{c}}$} & $\mathrm{Cl}$ & $42 \%$ \\
\hline 7 & $\mathrm{CH}_{2} \mathrm{Cl}_{2}$ & {$[\mathrm{Ir}]^{\mathrm{c}}$} & $\mathrm{Cl}$ & $0 \%$ \\
\hline 8 & $\mathrm{CH}_{3} \mathrm{CN}$ & {$[\mathrm{Ir}]^{\mathrm{c}}$} & $\mathrm{Cl}$ & $0 \%$ \\
\hline 9 & THF & - & $\mathrm{Cl}$ & $0 \%$ \\
\hline $10^{\mathrm{e}}$ & THF(e) & {$[\mathrm{Ir}]^{\mathrm{c}}$} & $\mathrm{Cl}$ & $0 \%$ \\
\hline 11 & THF & {$[\mathrm{Ir}]^{\mathrm{c}}$} & $\mathrm{F}$ & $0 \%$ \\
\hline 12 & THF & {$[\mathrm{Ir}]^{\mathrm{c}}$} & lb & $40 \%$ \\
\hline 13 & THF & {$[\mathrm{Ir}]^{\mathrm{c}}$} & |c & $31 \%$ \\
\hline 14 & THF & {$[\mathrm{Ir}]^{\mathrm{c}}$} & 1d & $12 \%$ \\
\hline
\end{tabular}

${ }^{a}$ NMR yield using $1,3,5$ trimethoxybenzene as internal standard; ${ }^{b}[R u]=$ $\mathrm{Ru}(\mathrm{bpy})_{3}\left(\mathrm{PF}_{6}\right)_{2},{ }^{\mathrm{c}}[\mathrm{Ir}]=\operatorname{Ir}\left(\mathrm{dF}\left(\mathrm{CF}_{3}\right) \mathrm{ppy}\right)_{2}(\mathrm{bpy})\left(\mathrm{PF}_{6}\right){ }^{\mathrm{d}}{ }^{\mathrm{d}} 16 \mathrm{~h}$ of blue LED irradiation $(477 \mathrm{~nm})$ instead of $24 \mathrm{~h},{ }^{\mathrm{e}} \mathrm{No} \mathrm{NiCl}_{2} . \mathrm{dme}$ was present.

Table 1. Optimisation of the reaction conditions
In these optimized conditions other electrophiles were tested. While no product was observed with the corresponding acyl fluoride derivative, a yield of $40 \%, 31 \%$ and $12 \%$ was obtained from respectively activated ester $\mathbf{1 b}$, mixed anhydrides $\mathbf{1 c}$ and mixed carbonate 1d (Entries 12-14, Table 1). ${ }^{14}$ Nevertheless, these yields were lower than the one previously obtained with benzoylchloride as partner. Therefore, we decided to continue this study with acyl chloride partners.

We first varied the silicate partner (scheme 2) keeping benzoyl chloride 1a as the electrophile. All primary radicals resulted in poor yields of products (below $10 \%$ ). The main side product in these reactions is the acylation of catechol which suggested that the limiting step is the too slow oxidation of the silicate allowing the catecholate moiety to react on the acyl chloride. ${ }^{19}$ More activated alpha acetoxysilicate resulted only in a slight yield increase and adding 6 equiv of benzoyl chloride for 1 equiv of silicate did not change it. Not surprisingly, tert-butyl silicate underwent little cross coupling. ${ }^{8 a}$ Secondary silicates proved however to be generally more rewarding since cyclopentyl, norbornane and cyclohexyl silicate precursors afforded the cross coupling products in $27 \%(3 \mathrm{~h})$, $49 \%(3 \mathrm{~g})$ and $64 \%(3 \mathrm{a})$ yield respectively. Finally, activated silicates such as the newly prepared (see $\mathrm{SI})$ methoxymethylene one $\left(\mathrm{E}_{\mathrm{ox}}=\right.$ $+0.71 \mathrm{~V}$ vs SCE $2 \mathrm{i}$ ) and benzyl derivatives gave the best results and provided highly enolizable ketones $\mathbf{3} \mathbf{i}, \mathbf{3} \mathbf{j}$ and $\mathbf{3 k}$ in very good yields, respectively $64 \%, 82 \%$ and $80 \%$.

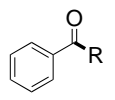

3b $(\mathrm{R}=n$-hex $), 5 \%{ }^{\mathrm{a}}$ $3 c\left(\mathrm{R}=\left(\mathrm{CH}_{2}\right)_{2} \mathrm{CN}\right), 7 \% \mathrm{a}$ 3d $\left(\mathrm{R}=\left(\mathrm{CH}_{2}\right)_{2} \mathrm{CF}_{3}\right), 10 \%$ a

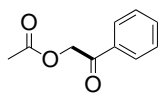

3 e, $23 \%$

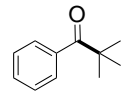

3f, $8 \%{ }^{a}$

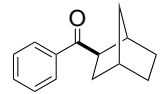

$3 g, 49 \%$

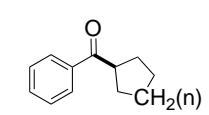
$3 a, n=2 \quad 64 \%$ 3h, $\mathrm{n}=1 \quad 27 \%$

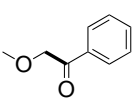

$3 i, 64 \%$

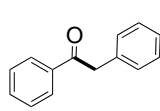

$3 \mathbf{j}, 82 \%$

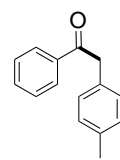

$3 k, 80 \%$ a NMR yield using 1,3,5 trimethoxybenzene as internal standard

Scheme 2. Silicate scope in the coupling reaction with benzoyl chloride

It appeared also judicious to compare the reactivities of the benzyl trifluoroborate and the benzyl silicate precursors in these conditions with no additive. The benzyl trifluoroborate 4 a afforded the desired product $\mathbf{3} \mathbf{j}$ with a yield of $50 \%$ by NMR (benzoic acid was also observed in the reaction mixture attesting the incomplete conversion of the reactant) compared to the $82 \%$ isolated from benzyl silicate $\mathbf{1} \mathbf{j}$ with full conversion of the acyl chloride (scheme $\mathbf{3}$ ) ( $10 \%$ of monoacylated product were also observed in that case). 


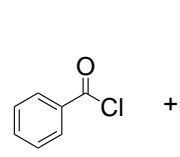

$1 a$

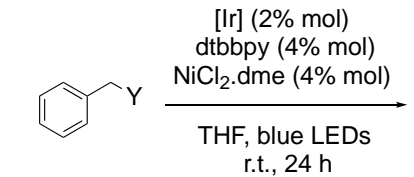

$\mathrm{Y}=\mathrm{BF}_{3} \mathrm{~K}, \mathbf{4 a}$

$\mathrm{Y}=[\mathrm{Si}], \mathbf{2 k}$

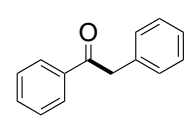

3j

$\mathrm{Y}=\mathrm{BF}_{3} \mathrm{~K}, 50 \% \mathrm{a}$ $\mathrm{Y}=[\mathrm{Si}], 82 \%$ a by NMR using 1,3,5 trimethoxybenzene as internal standard

Scheme 3. Comparison of the reactivity of the benzyl trifluoroborate and the benzyl silicate

In order to avoid the previously mentioned catechol acylation side reaction, we tried to employ miniaturized flow reactors to accelerate the desired photooxidative process. ${ }^{20}$

An initial flow set-up was assembled using a Schlenk flask and a recirculating pump (Scheme 4). The reagents were mixed by magnetic stirring inside the Schlenk flask protected from light, pumped through a PTFE tube $\left(1 / 16^{\prime \prime}\right.$ tubing, $134 \mathrm{~cm}, 0.67 \mathrm{~mL}$ at room temperature) under blue LED irradiation ( $477 \mathrm{~nm}$ ) which was used as the flow reactor and re-introduced into the Schlenk flask. The coupling of benzyl silicate $\mathbf{2} \mathbf{k}$ with benzoyl chloride was used as a model reaction and a yield of $\mathbf{4 3} \%$ for $\mathbf{3} \mathbf{j}$ was obtained in 3.8 hours within this flow reactor. Nevertheless the formation of a larger amount of mono and bis-acylated product was observed in contrast to the traces obtained with benzyl silicate in batch. This result can be easily explained by the fact that the side reaction does not need light and that it can occur inside the Schlenk reservoir.

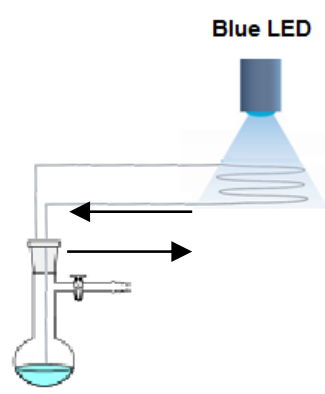

Scheme 4. Flow configuration with premixed reactants

Following this first attempt, a two flux process without recirculation was developed on the same scale as the previous batch reaction (scheme 5).
Batch:

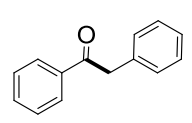

$24 \mathrm{~h}: 3 \mathbf{j}, 82 \%$

20mn: 3 j, $5 \%^{\mathrm{a}}$

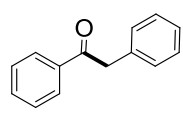

20mn: $\mathbf{3 j}, 70 \%$ $1 \mathrm{mn}: 3 \mathbf{j}, 20 \%^{\mathrm{a}}$

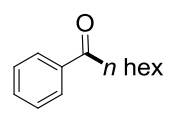

24h: $3 b, 5 \%^{a}$

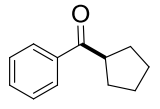

$24 \mathrm{~h}: 3 \mathrm{~h}, 27 \%$

\section{Flow:}

by NMR using 1,3,5 trimethoxybenzene as an internal standard

Scheme 5. Flow configuration with in-line micro reactor

One flux introduced the acyl chloride and the other one the nickel catalyst, the photocatalyst, the ligand and the silicate. The two flux $(\mathrm{F}=1.305 \mathrm{~mL} / \mathrm{h}$ ) were mixed within a glass milli-mixer (LTF-MX, $0.2 \mathrm{~mL}$ at room temperature) under blue LED irradiation $(477 \mathrm{~nm})$, and the mixture then flowed through a PTFE tubing (1/16" tubing, $134 \mathrm{~cm}, 0.67 \mathrm{~mL}$ at room temperature) under blue LED irradiation $(477 \mathrm{~nm})$. The resulting solution was collected in the dark and the desired product isolated directly after by chromatography. A good yield $(70 \%)$ of the cross-coupling product $\mathbf{3 j}$ was obtained in only 20 minutes with total conversion of the acyl chloride with this flow setup $(20 \%$ of the monoacylated product and traces of the bisacylated adduct were also observed), while a similar yield (81\%) on the same scale can be obtained in a batch reactor after 24 hours. The flow reaction setup gives rise to a shorter reaction time, hence a higher energy efficiency, not to mention the ease of scaling-up with the flow chemistry.

Encouraged by these series of preliminary findings and exploring the synthetic potential of this new transformation, we examined the influence of the acyl chloride partner (scheme $\mathbf{6}$ ) using $\mathbf{2 a}$ and $\mathbf{2 j}$ as radical sources. The highly electrophilic para- $\mathrm{CF}_{3}$ substituted benzoyl choride mainly led to the formation of the acylated catechol (mono-acylated and bi-acylated products) with poor yields of cross coupling ketones $\mathbf{3 I}$ (8\%) and $\mathbf{3 q}$ (16\%). In contrast, electron richer benzoyl chlorides afforded the corresponding ketones in moderate to good yields (respectively 51\% and 52\% for the cyclohexyl silicate and $81 \%, 71 \%$ for the benzyl silicate). To our delight, primary and secondary alkyl acylchlorides provided the products in very high yields leading to ketones with various substitution patterns, featuring for examples cyclopropyl and cyclobutyl benzylketones (3zb and $\mathbf{3 z d}$ ). Of note double coupling from a diacylchloride was possible (diketone 3ze). Finally, highly enolizable dibenzyl ketones such as $\mathbf{3} \mathbf{w}-\mathbf{z}$ could be prepared through this method. 


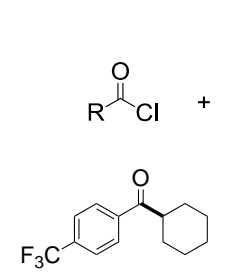

3I, $8 \%$
[Ir] $(2 \% \mathrm{~mol})$

THF, blue LEDs $\mathrm{R}^{\mathrm{O}} \mathrm{R}^{\prime}$ r.t., $24 \mathrm{~h}$

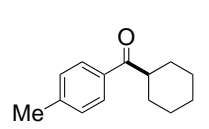
dtbbpy $(4 \% \mathrm{~mol})$ $\mathrm{NiCl}_{2}$.dme $(4 \% \mathrm{~mol})$ 3n, $52 \%$

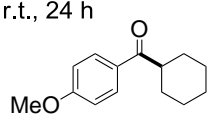

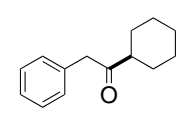

3o, $31 \%$

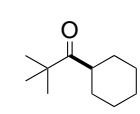

$3 p, 0 \%$

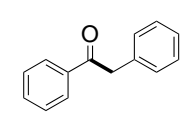

$3 j, 82 \%$

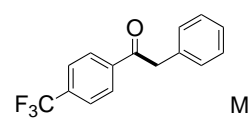

$3 q, 16 \%$

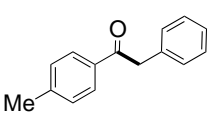

$3 r, 71 \%$<smiles>COc1ccc(C(=O)Cc2ccccc2)cc1</smiles>

3s, $81 \%$

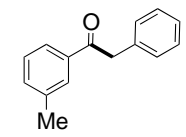

3t, $71 \%$

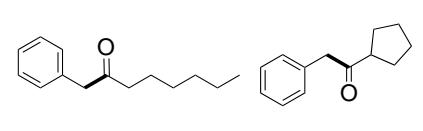

$3 u, 89 \%$

$3 v, 86 \%$

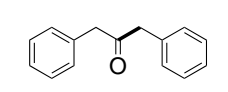

$3 w, 88 \%$

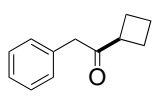

3zb, $63 \%$

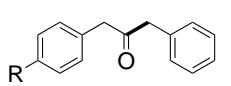
$3 x, R=F \quad 46 \%$ $3 y, R=$ OMe $38 \%$

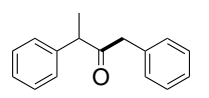

$3 z, 48 \%$
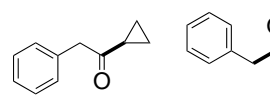

3zd, $90 \%$

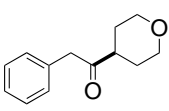

$3 z c, 82 \%$

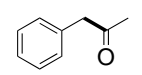

3za, $48 \%$

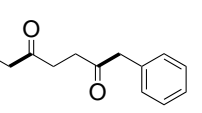

3ze, $40 \%$
Moreover, these ketones are valuable scaffolds for further elaboration. For instance, $\mathbf{3} \mathbf{j}$ has already been used to synthesize natural products or drugs as valdecoxib, ${ }^{21}$ scabanca (through a Bayer-Villiger oxidation) $)^{22}$ or tamoxifen. ${ }^{23}$

Based on our recent works and other groups ones on related silicate chemistry, ${ }^{8}$ the following mechanism can be reasonably proposed (Scheme 7). The excited photocatalyst readily oxidizes the silicate to generate an iridium(II) complex and a radical intermediate. Presumably, the latter adds onto the nickel(II) intermediate resulting from the oxidative addition of the acyl chloride partner onto nickel(0). The resulting nickel(III) complex undergoes reductive elimination releasing both the desired product and a nickel (I) species which is then further reduced by iridium(II) and regenerates the iridium(III) photocatalyst.

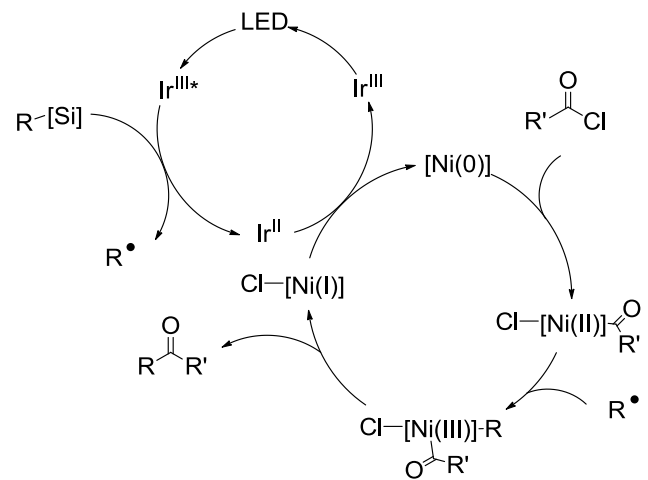

Scheme 7. Proposed mechanism

\section{Conclusions}

In a nutshell, a novel way of obtaining ketones by dual photoredox/Ni dual catalysis involving bis-catecholato silicates as radical sources and acyl chlorides as electrophiles. While the reaction proved unsatisfactory with primary silicates or highly electrophilic acid chlorides due to adventitious acylation of the catechol moieties, interesting yields of variously substituted ketones have been generally recorded. Notably the highly enolizable dibenzylic ketones could be prepared. Various applications of flow chemistry to such photoredox/nickel dual catalysis reaction have been disclosed and a shorter reaction time has been obtained.

\section{Experimental Section}

To a Schlenk flask was added the appropriate silicate (1.5 equiv), [Ir] (2 mol \%), 4,4'-di-tert-butyl-2,2'-dipyridyl (4 mol \%) and $\mathrm{NiCl}_{2}$.dme (4 mol \%). The Schlenk flask was sealed with a rubber septum and evacuated/purged with vacuum/argon cycles three times. Degassed THF (0.1 M) was introduced followed by addition of the electrophile 2 ( 1 equiv) and the reaction mixture was irradiated with blue LED $(477 \mathrm{~nm})$ at room temperature for $24 \mathrm{~h}$ under an argon atmosphere. The reaction mixture was diluted with diethyl ether, washed with aqueous saturated $\mathrm{K}_{2} \mathrm{CO}_{3}$ solution (2 times), brine ( 2 times), dried over $\mathrm{MgSO} 4$ and evaporated under reduced pressure. The crude residue was purified by flash chromatography.

\section{Conflicts of interest}

There are no conflicts to declare

\section{Acknowledgements}

We thank Sorbonne Université, CNRS and ANR-17-CE07-0018 HyperSilight (PhD grant to EL) for financial support. We also thank Khaoula Jaoudi for the CV of $\mathbf{2 i}$. 


\section{Notes and references}

${ }^{1}$ The Carbonyl Group, Patai's Chemistry of Functional Groups Vol 1 \& 2, 1970, J. Wiley \& Sons.

${ }^{2}$ For reviews, see: (a) Y.-Y. Gui, L. Sun, Z.-P. Lu and D.-G. Yu, Org. Chem. Front. 2016, 3, 522; (b) B. L. Tóth, O. Tischler and Z. Novàk, Tetrahedron Lett., 2016, 57, 4505; (c) M. D.; Levin, S. Kim and F. D. Toste, ACS Cent. Sci. 2016, 2, 293; (d) K. L. Skubi, T. R. Blum and T. P. Yoon, Chem. Rev., 2016, 116, 10035; (e) J. Twilton, C. Le, P. Zhang, R. W. Evans and D. W. C. MacMillan, Nat. Rev. Chem., 2017, 1, 0052. ${ }^{3}$ (a) Z. Zuo, D. T. Ahneman, L. Chu, J. A. Terrett, A. G. Doyle and D. W. C. MacMillan, Science, 2014, 345, 437.

4 J. C. Tellis, D. N. Primer and G. A. Molander, Science, 2014, 345, 433.

${ }^{5}$ (a) A. Noble, S. J. McCarver and D. W. C. MacMillan, J. Am. Chem. Soc., 2015, 137, 624; (b) S. J. McCarver, J. X. Qiao, J. Carpenter, R. M. Borzilleri, M. A. Poss, M. D. Eastgate, M. Miller and D. W. C. MacMillan, Angew. Chem. Int. Ed., 2016, 55, 1; (c) C. P. Johnston, R. T. Smith, S. Allmendinger and D. W. C. MacMillan, Nature, 2016, 536, 322; (d) N. A. Till, R. T. Smith and D. W. C. MacMillan, J. Am. Chem. Soc., 2018, 140, 5701.

${ }^{6}$ D. T. Ahneman and A. G. Doyle, Chem Sci., 2016, 7, 7002.

7 (a) J. K. Matsui and G. A. Molander, Org. Lett., 2017, 19, 436; (b) Y. Yamashita, J. C. Tellis and G. A. Molander, Prot. Natl. Acad. Sci. USA, 2015, 112, 12016; (c) E. E. Stache, T. Rovis, A. G. Doyle, Angew. Chem. Int. Ed., 2017, 56, 3679; (d) X.-Y. Yu, Q.-Q. Zhou, P.-Z. Wang C.-M. Liao, J.-R. Chen and W.-J. Xiao, Org. Lett., 2018, 20, 421; (e) F. Lima, M. A. Kabeshov, D. N. Tran, C. Battilocchio, J. Sedelmeier, G. Sedelmeier, B. Schenkel and S. V. Ley, Angew. Chem. Int. Ed., 2016, 55, 1; (g) F. Lima, L. Grunenberg, H. B. A. Rahman, R. Labes, J. Sedelmeier and S. V. Ley, Chem.Commun., 2018, 54, 5606.

8 (a) V. Corcé, L.-M. Chamoreau, E. Derat, J.-P. Goddard, C. Ollivier and L. Fensterbank, Angew. Chem. Int. Ed., 2015, 54, 11414; (b) M. Jouffroy, D. N. Primer and G. A. Molander, J. Am. Chem. Soc., 2016, 138, 475; (c) C. Lévêque, L. Chennenberg, V. Corcé, J.-P. Goddard, C. Ollivier and L. Fensterbank, Org. Chem. Front., 2016, 3, 462; (d) K. Lin, R. J. Wiles, C. B. Kelly, G. H. M. Davies and G. A. Molander, ACS. Catal., 2017, 7, 5129; (e) N. R. Patel, C. B. Kelly, M. Jouffroy and G. A. Molander, Org. Lett., 2016, 18, 764; (f) B. A. Vara, X. Li, S. Berritt. C. R. Walters, E. J. Petersson and G. A. Molander, Chem. Sci., 2018, 9, 336; (g) K. D. Raynor, G. D. May, U. K. Bandarage and M. J. Boyd, J. Org. Chem., 2018, 83, 1551; (h) T. Guo, L. Zhang, X. Liu, Y. Fang, X. Jin, Y. Yang, Y. Li, B. Chen and M. Ouyang, Adv. Synth. Catal., 2018, 360, 4457; (i) For a very recent report, see: A. Cartier, E. Levernier, V. Corcé, T. Fukuyama, A. -L. Dhimane, C. Ollivier, I. Ryu and L. Fensterbank, Angew. Chem. Int. Ed., 2019, 58, 1789.

${ }^{9}$ (a) Á. Gutiérrez-Bonet, J. C. Tellis, J.R K. Matsui, B. A. Vara, and G. A. Molander, ACS Catal., 2016, 6, 8004; (b) J. K. Matsui, S. B. Lang, D. R. Heitz, and Gary A. Molander, ACS Catal., 2017, 7, 2563; (c) K. Nakajima, S. Nojima and Y. Nishibayashi, Angew. Chem. Int. Ed., 2016, 55, 14106.

10 (a) H. Yue, C. Zhu and M. Rueping, Angew. Chem. Int. Ed., 2018, 57, 1371; (b) T. Knauber, R. Chandrasekaran, J. W. Tucker, J. M. Chen, M. Reese, D. A. Rankic, N. Sach, and Christopher Helal, Org.Lett., 2017, 19, 6566.

11 (a) Y. -Y. Gui, L.-L. Liao, L. Sun, Z. Zhang, J-H. Ye, G. Shen, Z.-P. Lu, W.-J. Zhou and D.-G. Yu, Chem.Commun., 2017, 53,1192.

12 For recent books see : (a) Chemical Photocatalysis, Eds. B. König, DeGruyter Berlin, 2013; (b) Photochemically generated intermediates in Synthesis, Eds A. Albini and M. Fagnoni, Wiley,
Hoboken, 2013; (c) For a recent review, see: (c) L. Marzo, S. K. Pagire, O. Reiser, B. König, Angew. Chem. Int. Ed., 2018, 57, 10034.

13 For recent reviews: (a) C. Raviola, S. Protti, D. Ravelli and M. Fagnoni, Green Chem. 2019, DOI: 10.1039/C8GC03810D; (b) A. Banerjee, Z. Lei and M.-Y. Ngai, Synthesis 2019, 51, 303; (c) M. Rueping, C. Vila, R. M. Koenigs, K. Poscharny and D. C. Fabry, Chem. Commun., 2011, 47, 2360; (d) L. Chu, J. M. Lipshultz and D. W. C. MacMillan, Angew. Chem. Int. Ed., 2015, 54, 7929; (e) H.-T. Qin, S.W. Wu, J.-L. Liu and F.Liu, Chem. Commun., 2017, 53, 1696; (f) G. F. P. de Souza, J. A. Bonacin and A. G. Salles, J. Org. Chem., 2018, 83, 8331; (g) L. Capaldo, R. Riccardi, D. Ravelli and M. Fagnoni, ACS Catal., 2018, 8, 304; (h) M. Zhang, J. Xie and C. Zhu, Nat. Commun., 2018, 9, 3517.

14 (a) C. L. Joe and A. G. Doyle, Angew. Chem. Int. Ed, 2016, 55, 4040; For the use of in situ generated mixed carbonates, see also: (b) J. Amani and G. A. Molander, Org. Lett. 2017, 19, 3612; (c) S. A. Badir, A. Dumoulin, J. K. Matsui and G. A. Molander, Angew. Chem. Int. Ed, 2018, 57, 6610.

15 (a) J. Amani and G. A. Molander, J. Org. Chem., 2017, 82, 1856; (b) J. Amani, E. Sodagar and G. Molander, Org. Lett., 2016, 18, 732.

${ }^{16}$ H. Uoyama, K. Goushi, K. Shizu, H. Nomura and C. Adachi, Nature, 2012, 492, 234.

17 For a reevaluation of the reduction and oxidation potentials of the excited state of 4CZIPN, see: F. L. Vaillant, M. Garreau, S. Nicolai, G. Gryn'ova, C. Corminboeuf and J. Waser, Chem. Sci., 2018, 9, 5883.

18 (a) C. Lévêque, L. Chenneberg, V. Corcé, C. Ollivier and L. Fensterbank, Chem. Commun., 2016, 52, 9877; (b) J. P. Phelan, S. B. Lang, J. S. Compton, C. B. Kelly, R. Dykstra, O. Gutierrez and G. A. Molander, J. Am. Chem. Soc., 2018, 140, 8037.

19 A series of blank experiments showed that bis-acetylated catechol was obtained in $15 \%$ and $9 \%$ from the reaction respectively of $n$-hexyl and cyclohexyl silicates (1.5 equiv) with 1 equiv of benzoyl chloride for $24 \mathrm{~h}$ in THF under blue LED irradiation (the same yield was obtained without irradiation).

${ }^{20}$ (a) D. Cambie, C. Bottecchia, N. J. W. Straathof, V. Hessel and T. Nöel, Chem. Rev., 2016, 116, 10276; (b) K. D. Raynor, G. D. May, U. K. Bandarage and M. J. Boyd, J. Org. Chem., 2018, 83, 1551; (c) J. W. Tucker, Y. Zhang, T. F. Jamison and C. R. J. Stephenson, Angew. Chem. Int. Ed., 2012, 51, 4144; (d) Z. J. Garlets, J. D. Nguyen and C. R. J. Stephenson, Isr. J. Chem., 2014, 54, 351; (e) T. J. DeLano, U. K. Bandarage, N. Palaychuk, J. Green and M. J. Boyd, J. Org. Chem., 2016, 81, 12525; (f) N. Palaychuk, T. J. DeLano, M. J. Boyd, J. Green and U. K. Bandarage, Org. Lett. 2016, 18, 6180; (g) H.-W. Hsieh, C. W. Coley, L. M. Baumgartner, K. F. Jensen and R. I. Robinson, Org. Process Res. Dev., 2018, 22, 542; (h) N. El Achi, M. Penhoat, Y. Bakkour, C. Rolando and L. Chausset-Boissarie, Eur. J. Org. Chem., 2016, 4284; (i) M. Neumann and K. Zeitler, Org. Lett., 2012, 14, 2012.

21J. J. Talley, D. L. Brown , J. S. Carter, M. J. Graneto, C. M. Koboldt, J. L. Masferrer, W. E. Perkins, R. S. Rogers, A. F. Shaffer, Y. Y. Zhang, B. S. Zweifel and K. Seibert, J. Med. Chem., 2000, 43, 775.

${ }^{22} \mathrm{~F}$. Toda, M. Yagi and K. Kiyoshige, Chem. Commun., 1988, 0, 958

${ }^{23}$ R. J. McCague, J. Chem. Soc. Perkin Trans., 1987, 1, 1011. 